\title{
ANÁLISE DOS 4 EIXOS DA OFERTA DE CONTEÚDO CONTEXTUAL EM SITES DE NOTÍCIAS: empresa, conteúdo, usuário e comunidade
}

\author{
Augusto de Freitas Lohmann \\ ESDI / UERJ \\ augustolohmann@gmail.com
}

\begin{abstract}
Resumo: O objetivo deste artigo é aprofundar o entendimento da categorização da oferta de conteúdo contextual em sites de notícias, de maneira a obter informações que auxiliem na identificação de um modelo que ofereça a melhor experiência de uso (do ponto de vista do conteúdo oferecido). No artigo, serão apresentados os 4 eixos da macro categorização da oferta de conteúdo contextual, conforme identificado pelo próprio autor em pesquisa prévia (LOHMANN, 2013). A seguir, serão observados quais dos eixos apresentados são utilizados nos elementos de oferta de conteúdo em alguns dos principais sites de notícias do Brasil e do Mundo, e de que maneira se dá essa utilização. A partir desse mapeamento, serão apresentadas possíveis limitações encontradas nos modelos de oferta de conteúdo analisados e discutidas as possíveis soluções que, do ponto de vista conceitual, otimizariam a experiência de navegação dos usuários dos sites de notícias.
\end{abstract}

Palavras-chave: Categorização, Conteúdo, Contextual, Navegação, Notícias.

\begin{abstract}
The aim of this paper is to deepen the understanding of the categorization of offering contextual content on news sites, in order to obtain information to assist in the identification of a model that provides the best user experience (from the point of view of content offered). Will be given the 4 axes of categorization macro offering contextual content in the article, as identified LOHMANN (2013). The following will be observed which presented the axes are used in the provision of content elements in some major news sites in Brazil and the world, and how it gives such use. From this mapping, the deficiencies found in models of offering contextual content analyzed and discussed possible solutions that, from a conceptual standpoint, optimize the browsing experience of users of news sites will be identified.
\end{abstract}

Keywords: Categorization, Content, Context, Navigation, News. 


\section{INTRODUÇÃO}

O consumo noticioso no ambiente digital provocou uma ruptura no modelo vigente de organização e oferta de conteúdo. Enquanto no jornalismo impresso, o conteúdo noticioso era organizado de uma única maneira (definida pela equipe editorial do jornal), limitando a participação do leitor no processo de construção do fluxo narrativo, no meio digital as possibilidades são múltiplas, baseadas em diferentes critérios, e permitindo ao agora usuário uma maior possibilidade de estabelecer e exercer seu próprio fluxo de consumo do conteúdo noticioso. Dessa forma, conforme apresentado pelo próprio autor em artigo prévio (LOHMANN, 2013), ao mesmo tempo em que encontra mais liberdade, o usuário vê diminuída sua percepção de controle sobre uma hipotética totalidade do conteúdo:

"Ainda no ambiente noticioso, enquanto o consumo do conteúdo em um meio físico (o jornal impresso, por exemplo) e o modelo de edições periódicas trazem a noção de um conteúdo finito, da completude da absorção das informações selecionadas pelo corpo editorial do jornal, o ambiente virtual/digital rompe com esse modelo de edições fechadas e delimitadas, o que, em paralelo a atualização constante de conteúdo e aos inúmeros fluxos possíveis, diminui nos usuários a percepção de controle sobre o conteúdo. Nesse contexto, a presença de elementos de navegação contextuais que ofereçam fluxos de navegação bem estruturados possibilitam ao usuário manter-se apto a percorrer os principais conteúdos e a interagir com a informação de seu interesse de diferentes maneiras." (LOHMANN, A. 2013)

Nesse sentido, pensar a oferta de novos conteúdos para que o usuário exerça sua navegação em um site de notícias é uma das maneiras de minimizar a sensação de infinitude de conteúdo provocada nesse contexto pós-digitalização dos meios comunicacionais.

Além da importância como solução de navegação, os elementos de navegação oferecidos pelos sites de notícias ganham relevância quando observado o comportamento dos usuários no consumo da informação noticiosa. Em pesquisa realizada pelo "The Pew Research Center's Project for Excellence in Journalism" (figura 1), verifica-se que as homepages vêm perdendo relevância como porta de entrada dos usuários, que cada vez mais acessam diretamente a página de conteúdo (por exemplo, a matéria jornalística) tendo como origem dessa navegação os buscadores, as redes sociais ou outras fontes externas. 


\section{Social media is not an overwhelming driver of news (yet)}

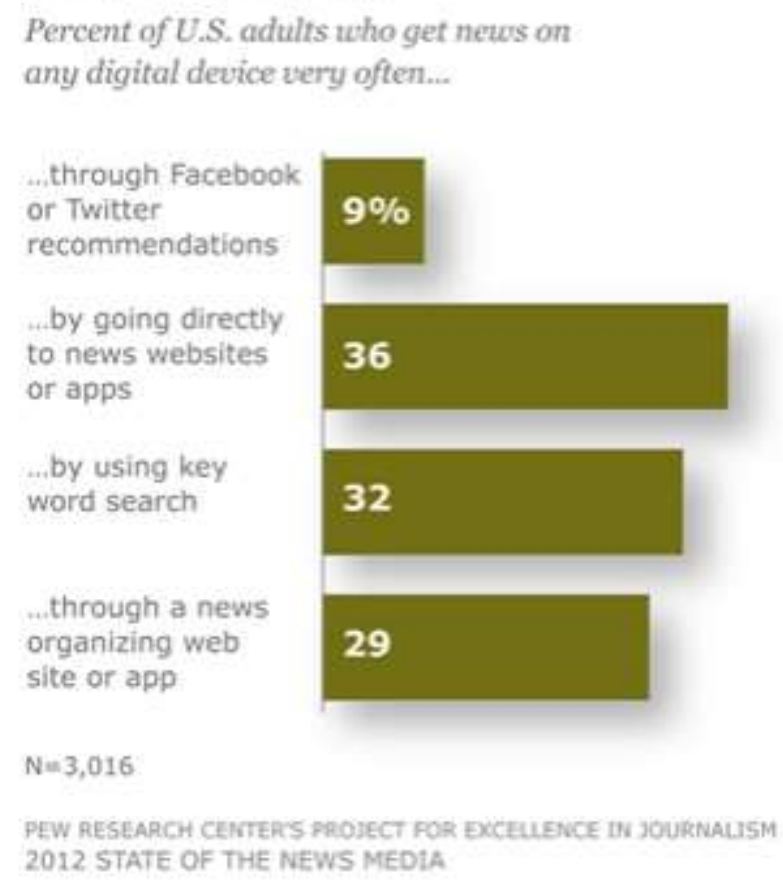

Figura 1 - Percentual de americanos que consomem notícias em sites de acordo com a origem do tráfego.

Fonte: Pew Research Center's Project for Excellence in Journalism, 2012.

De acordo com a pesquisa, apenas $36 \%$ dos usuários acessa diretamente um site de notícias a partir da url da página inicial do site. Os acessos originados de buscadores, redes sociais ou outras fontes externas, quando consolidados, já representam a maioria dos acessos, e nesses casos, e porta de entrada se dá justamente a partir da página de conteúdo, e não das homepages dos sites de notícias.

Dessa forma, conforme afirmou LOHMANN (2013), cresce em importância o papel das páginas internas de conteúdo, que adquirem status de landing pages (páginas de entrada) e que, portanto, têm em seus elementos de navegação o fator que pode definir a retenção ou o abandono de um usuário em seu processo de navegação:

"(...)a partir do momento em que o usuário encontra-se no contexto do site noticioso, e que a landing page mais comum é a própria página de conteúdo - e não mais a homepage - a navegação acontece cada vez menos orientada à organização de leitura sugerida editorialmente nas capas e mais estruturada a partir de elementos de navegação contextual, onde as possibilidades para a sequência da leitura/navegação se dão a partir de elementos disponibilizados na própria página de conteúdo, de forma muito mais orgânica e estruturada." (LOHMANN, A. 2013)

Ao mesmo tempo, do ponto de vista da experiência do usuário, é importante identificar que, quanto mais precisa e eficiente for a oferta de novos conteúdos para leitura, menor a chance do usuário se frustrar e abandonar sua navegação, e menor a chance desse mesmo usuário estabelecer uma relação de engajamento com o site 
noticioso. De acordo com o artigo "Whay you think you know about the web is wrong" (HAILE, T. 2014), o tempo que o usuário permanece navegando em um site é uma estatística de fundamental importância, interferindo de maneira decisiva na possibilidade de retorno e fidelização deste usuário ao portal noticioso:

"Pesquisas realizadas pelo site Chartbeat indicaram que usuários que permaneceram por pelo menos 3 minutos navegando em um site tem uma tendência a retornar ao mesmo site 2 vezes maior em relação a usuários que ficam por menos de 3 minutos." (HAILE, 2014)

Da mesma forma, em pesquisa da "Pew Research Center" (figura 2), observa-se que usuários que acessam diretamente um site de notícias, a partir de sua homepage, permanecem por 3 vezes mais tempo, em média, do que usuários que acessam a partir de redes sociais ou mecanismos de busca (e que, consequentemente, iniciam seu acesso a partir das páginas de conteúdo).

\section{Referral Traffic to News Sites}

Average monthly...

Minutes per Visit

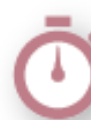

Visitors who..

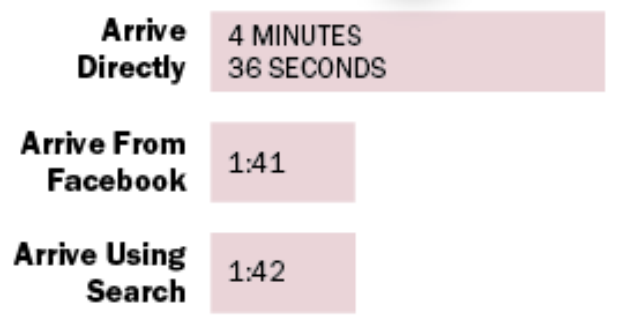

Pages per Visitor

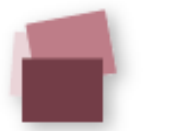

24.8

PAGES

4.2

4.9
Visits per Visitor

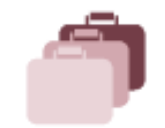

10.9

VISITS

2.9

3.1

Aggregation of all sites, average of April, May and June, 2013. PEW RESEARCH CENTER

Figura 2 - Métricas de navegação em sites de notícias (minutos por visita, páginas por visita e visitas por visitante) a partir de diferentes fontes de tráfego (direto, Facebook ou buscadores).

Fonte: Pew Research Center, 2013.

Além disso, o número de páginas por visita e o número de visitas por mês é, em media, 6 e 4 vezes maior, respectivamente, entre os usuários que acessam o site diretamente pela homepage (tráfego direto). Tais números corroboram a hipótese de que as páginas internas dos sites noticiosos não exercem de maneira plena seu papel de landing pages no estímulo ao engajamento e a um maior tempo de navegação do usuário.

Dessa forma, pensar a respeito da categorização e da oferta de conteúdo contextual no ambiente noticioso se apresenta como uma questão de extrema relevância na tentativa de se avançar na busca por melhorias na experiência de uso dos sites de notícias. 


\section{JUSTIFICATIVA E DESENVOLVIMENTO}

Com relação aos fluxos de navegação possíveis a partir do momento em que o usuário já se encontra em uma página de conteúdo de um site de notícias, conforme apresentado inicialmente em LOHMANN (2013), "(...)identificou-se a possibilidade de uma macro categorização desses fluxos, baseada no tipo de relação que estes estabelecem com os elementos envolvidos na navegação do usuário."

Nesse sentido, entende-se que a oferta de conteúdo contextual pode ser categorizada em 4 grandes eixos: Empresa, Conteúdo, Usuário e Comunidade (figura $3)$.

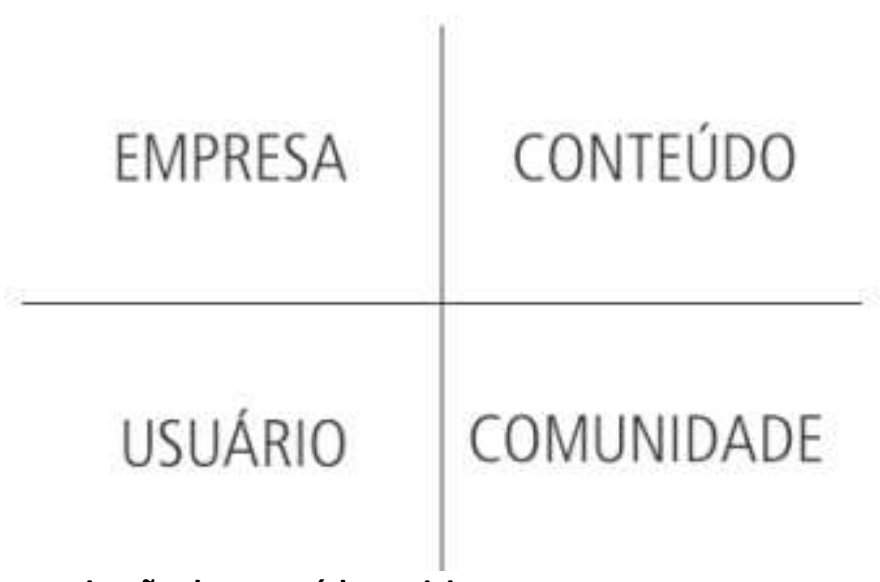

Figura 3 - eixos da categorização do conteúdo noticioso.

Fonte: Elaborado pelo autor, com base na pesquisa realizada.

O eixo "Empresa" contempla a oferta de conteúdo contextual cujos critérios são definidos pela empresa noticiosa, ou seja, é oferecido o que a empresa considera mais relevante jornalisticamente para o usuário. Em um contexto de elementos de navegações organizados pelo eixo editorial, ao priorizar o ponto de vista da empresa jornalística, são deixados de lado aspectos referentes aos outros três eixos, como o conteúdo que estava sendo previamente acessado pelo usuário, a experiência de navegação de toda a comunidade que utiliza o mesmo site e às individualidades do próprio usuário.

O eixo de oferta pelo "Conteúdo" contempla a oferta de navegação contextual baseada no conteúdo noticioso que estava sendo previamente acessado na experiência de navegação. Ou seja, o acesso do usuário a um determinado conteúdo fornece as informações para que a oferta de novos fluxos tenha relação com aquele conteúdo original, ao qual foi manifestado um interesse prévio por parte do usuário. Em um contexto de elementos de navegações baseados nesse eixo, ao priorizar a estreita relação com o conteúdo, são deixados de lado aspectos referentes ao ponto de vista da empresa noticiosa, bem como aspectos referentes a experiência de navegação de toda a comunidade que utiliza o mesmo site e às individualidades do próprio usuário.

O eixo baseado em características do "Usuário" contempla a oferta de conteúdo contextual a partir de individualidades do próprio usuário que acessa o site, seja por informações que ele forneça de maneira ativa, seja por um acompanhamento 
de sua experiência de navegação. Nesse contexto, ao priorizar somente o conteúdo que seja teoricamente mais atrativo para o usuário em função de seu gosto pessoal, os critérios de relevância relacionados à empresa, ao conteúdo e a comunidade são deixados de lado. Nesse sentido, Eli Pariser aponta o problema dos chamados "filtrosbolhas", onde o usuário é privado de determinados conteúdos baseado em uma análise subjetiva a respeito do seu gosto pessoal:

"Então, eu realmente penso que isto é um problema. E eu acho que, se você pegar todos estes filtros juntos, você pega todos estes algoritmos, você tem o que eu chamo de filtro-bolha. E o seu filtro-bolha é o seu próprio, pessoal e único universo de informação com o qual você vive 'on-line'. E o que está no seu filtro-bolha depende de quem você é, e depende do que você faz. Mas a questão é que você não decide o que entra. E mais importante, você, na verdade, não vê o que fica de fora." (PARISER)

O eixo denominado "Comunidade" contempla a oferta de conteúdo contextual baseada em características da maioria dos usuários que compõem a comunidade que acessa o site. Nesse caso, os outros 3 eixos tenderiam a ser deixados de lado, privando o usuário do recebimento de determinados conteúdos que possam ser relevantes, mesmo que não o sejam para a comunidade de usuários como um todo.

A partir da identificação conceitual desses 4 eixos para a categorização do conteúdo contextual em sites noticiosos, a presente pesquisa tem por objetivos analisar a oferta desse tipo de conteúdo em alguns dos principais sites de notícias do Brasil e do mundo.

Dessa forma, como proposta metodológica, foram selecionadas 3 páginas de conteúdo jornalístico dos seguintes sites: G1; O Globo e The New York Times. A escolha dos 3 sites é arbitrária e, neste momento, meramente ilustrativa, servindo como uma amostragem da infinidade de sites noticiosos existentes. Na visão do autor, a avaliação da navegação contextual nos sites mencionados à luz dos eixos de categorização propostos é suficiente para testar a aplicabilidade do método e exemplificar seu funcionamento, visando futura avaliação em uma maior quantidade de sites noticiosos.

Os resultados obtidos servem de subsídios para a sequência da pesquisa do autor, na tentativa de identificar se os diferentes eixos de oferta de conteúdo geram diferenças substanciais no tempo de retenção do usuário na página ou na sua percepção de uma melhor experiência de uso.

\section{RESULTADOS E CONCLUSÃO}

$\mathrm{Na}$ análise da página de conteúdo do site G1 (http://www.g1.globo.com), identificou-se a presença de 4 elementos com oferta de navegação contextual, conforme assinalado na figura 4, em amarelo.

O primeiro deles, na parte superior da coluna da direita, oferece outras notícias de assuntos relacionados ao conteúdo da página em questão. Sendo assim, o elemento poderia ser categorizado no eixo "conteúdo". Ainda na coluna da direita, abaixo desse elemento, encontra-se o box denominado "Primeira Página", com oferta de notícias que estão na homepage do site, independente do assunto a que se referem. Neste caso, o elemento é categorizado no eixo "editorial". 

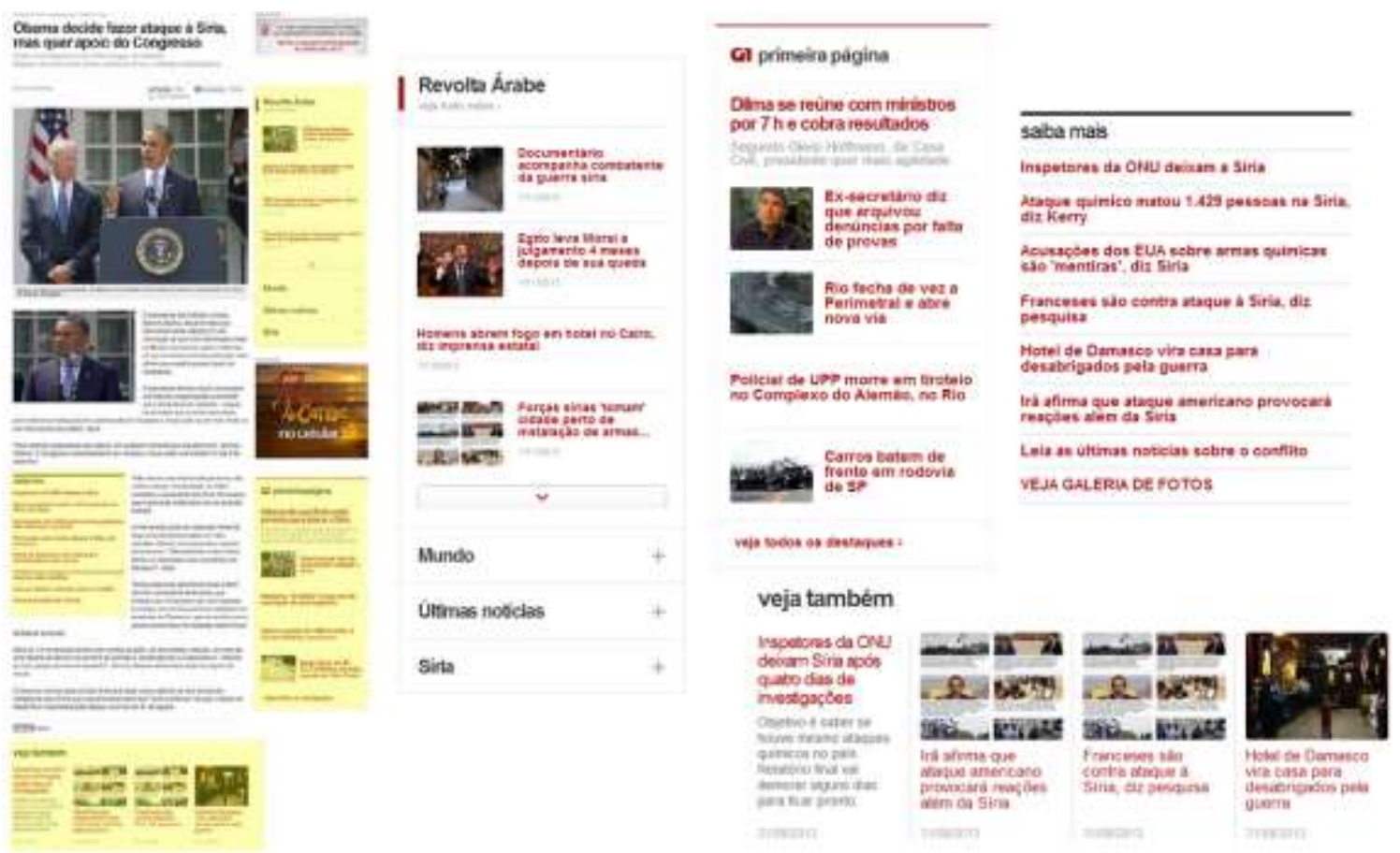

Figura 4 - Elementos de navegação contextual (destacados em amarelo) em uma página de matéria noticiosa do site $\mathbf{G 1}$ (http://www.g1.globo.com).

Fonte: Elaborado pelo autor, com base em captura de elementos de páginas de notícias do portal G1.

Outro elemento identificado na página de matéria do portal G1 foi o box denominado "Saiba Mais", presente na área de texto da notícia. Esse box também oferece conteúdo relacionado ao assunto da matéria em questão (a exemplo do primeiro elemento analisado), podendo portanto ser relacionado ao eixo de "conteúdo". Ao final da página, o último elemento de oferta de conteúdo contextual é denominado "Veja Também", e oferece mais matérias relacionadas ao conteúdo acessado, sendo novamente categorizado dentro do eixo de "conteúdo".

Sendo assim, observa-se que o portal G1 apresenta em suas páginas de conteúdo 4 elementos principais de oferta de conteúdo contextual, sendo 1 relacionado ao eixo "Editorial" e 3 associados ao eixo "Conteúdo". É importante destacar que, apesar de apresentar 3 elementos organizados pelo viés da relação com o conteúdo, existem regras de programação que impedem a oferta de conteúdo duplicado nestes elementos.

$\mathrm{Na}$ análise do site do jornal O Globo (http://www.oglobo.com.br), foram identificados 5 elementos para oferta de conteúdo contextual, sendo 4 deles posicionados na coluna da direita (figura 5). 


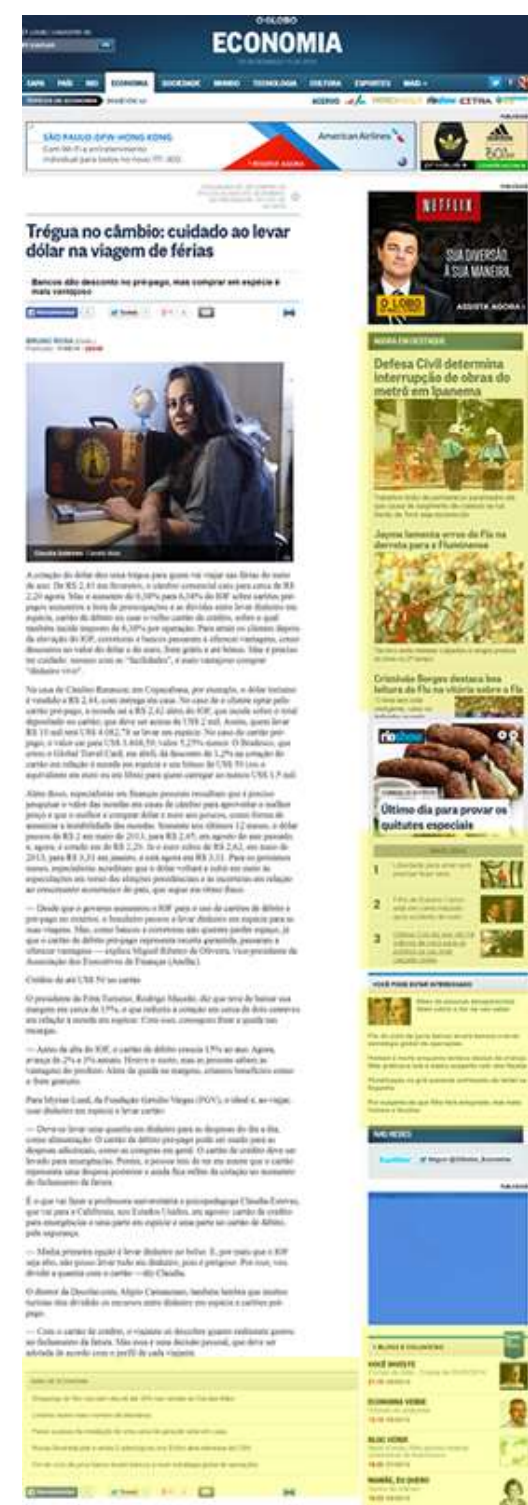

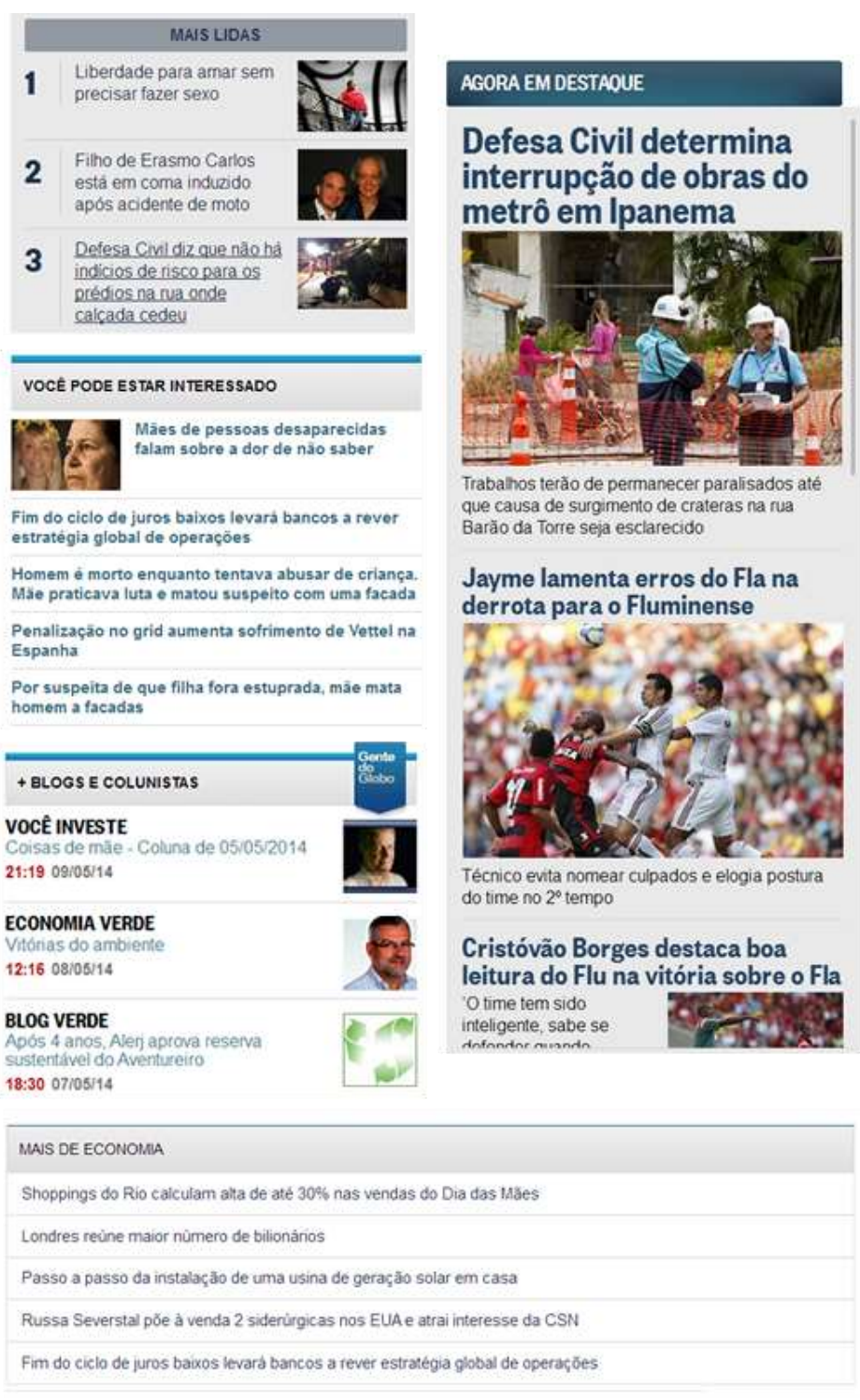

Figura 5 - Elementos de navegação contextual (destacados em amarelo) em uma página de matéria noticiosa do site do jornal O Globo (http://www.oglobo.com.br).

Fonte: Elaborado pelo autor, com base em captura de elementos de páginas de notícias do site do jornal O Globo.

O primeiro deles é denominado "Agora em Destaque" e oferece o conteúdo da homepage do site, ou seja, o que é relevante do ponto de vista da empresa noticiosa. Sendo assim, caracteriza-se como um elemento do eixo "Editorial". Logo abaixo, o elemento denominado "Mais Lidas" oferece as 3 notícias mais lidas de todo o site. Sendo assim, é um elemento relacionado ao eixo "Comunidade".

Na mesma coluna, mais abaixo, foi identificado o box "Você pode estar interessado", que oferece conteúdo relacionado ao assunto da notícia acessada, sendo portanto um elemento do eixo "Conteúdo". Ao final da coluna, é apresentado o elemento "Blogs e Colunistas", onde são oferecidos links para páginas de blogueiros e colunistas previamente selecionados pela equipe editorial do site (eixo editorial). 
Ainda na página de conteúdo do site d'O Globo, quase no rodapé, identifica-se o elemento "Mais de Economia", com oferta de notícias do mesmo assunto do conteúdo acessado (eixo "conteúdo").

Sendo assim, dos 5 elementos de oferta de conteúdo contextual identificados, 2 deles podem ser associados ao eixo "Editorial", outros 2 ao eixo "Conteúdo" e 1 ao eixo "Comunidade".

Já a página de conteúdo do site norte-americano "The New York Times" (http://www.nytimes.com) apresenta 4 grandes elementos para oferta de navegação contextual. O primeiro deles, logo no topo da página, traz notícias editorialmente selecionadas por sua relevância jornalística. Nesse sentido, é um elemento que se enquadra no eixo "Editorial".

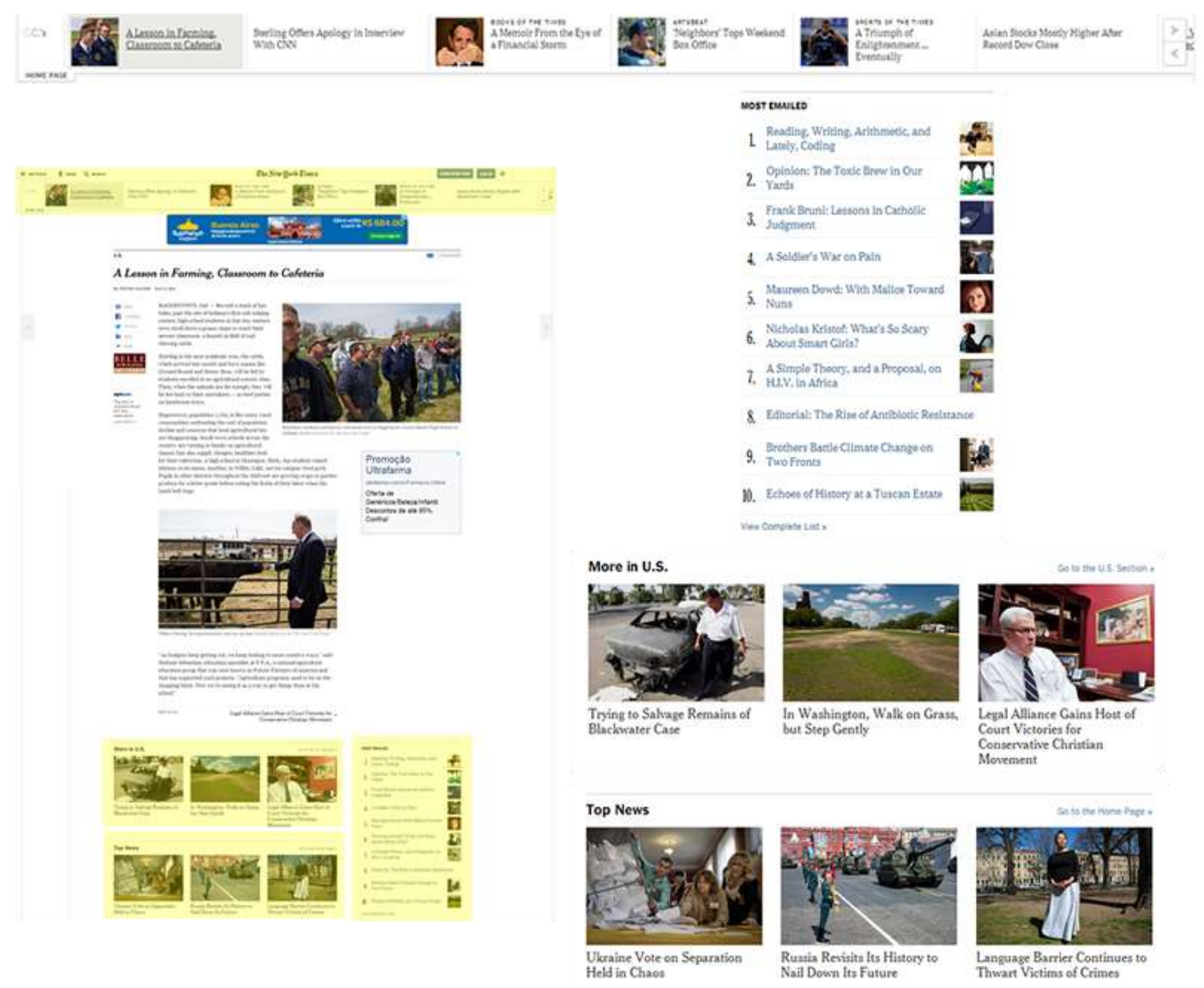

Figura 6 - Elementos de navegação contextual (destacados em amarelo) em uma página de matéria noticiosa do site do jornal The NY Times (http://www.nytimes.com).

Fonte: Elaborado pelo autor, com base em captura de elementos de páginas de notícias do site do jornal The NY Times.

Ao final da página, mais 3 elementos para navegação contextual se fazem presentes: "More in teh U.S", oferecendo mais notícias relacionados ao tema do conteúdo da página em questão (eixo "Conteúdo"); "Top News", oferecendo as notícias mais lidas do site (eixo "Comunidade"); e "Most Emailed", que apresenta as 
matérias mais compartilhadas por email do site (eixo "Comunidade"). Dessa forma, a página de conteúdo do "The New York Times" apresenta 2 elementos de navegação relacionados ao eixo "Comunidade", 1 relacionado ao eixo "Conteúdo" e 1 relacionado ao eixo "Editorial".

Dessa maneira, os resultados encontrados indicam ser possível a identificação dos elementos de navegação contextual nas páginas de conteúdo dos sites de notícias e sua consequente categorização dentro de (pelo menos) um dos quatro eixos apontados neste artigo (Editorial, Conteúdo, Usuário e Comunidade). Sendo assim, uma posterior aplicação desta mesma metodologia em uma amostragem maior e mais representativa de sites noticiosos propiciaria a obtenção de dados de grande relevância para o entendimento da oferta de conteúdo contextual.

Eli Pariser afirma que a escolha do conteúdo a ser oferecido aos usuários cada vez mais é fruto do processamento de algoritmos complexos, que estariam substituindo o papel do editor humano nesse processo de curadoria:

"O que estamos vendo é mais uma passagem do bastão dos porteiros humanos para os algorítmicos. $E$ a questão é que os algoritmos não possuem ainda o tipo ética arraigada que os editores possuiam. Então, se os algoritmos serão os curadores do mundo para nós, se eles decidirão o que veremos e o que não veremos, então precisamos ter certeza de que eles não estarão atados apenas à relevância. Precisamos ter certeza que eles também nos mostrarão coisas que são desconfortáveis ou desfiadoras ou importantes" (PARISER, Eli)

Nesse sentido, corroborado pela afirmação de Pariser, o autor acredita que ainda haja um caminho a ser percorrido no entendimento dos modelos mentais pelos quais os usuários exercem sua navegação nos sites de notícias, de maneira a desenvolver algoritmos cada vez mais precisos na oferta de conteúdo verdadeiramente relevante em cada contexto.

Nos modelos atuais, a partir dos sites avaliados nessa pesquisa, foi possível observar que os elementos de navegação contextual em sua maioria são oferecidos em grande quantidade ao longo da página, e cada um deles normalmente está bastante relacionado a um dos quatro eixos de categorização apresentados. Entretanto, a utilização de elementos de navegação que contemplem somente um desses eixos de maneira isolada reforça o contexto de "bolhas", onde determinados conteúdos de alto grau de relevância poderiam não ser oferecidos para o usuário.

O autor acredita que, a todo e qualquer conteúdo noticioso, os quatro eixos de categorização propostos poderiam ser aplicados com níveis de relevância diferentes. Por exemplo, um conteúdo A pode ter alta relevância editorial, mas pouca relevância para o usuário, para a comunidade e em sua relação com o conteúdo acessado previamente. Já um conteúdo B poderia ter alta relevância para o usuário e em sua relação com o conteúdo acessado previamente, mas baixa relevância do ponto de vista editorial e da comunidade de usuários como um todo. Nesse contexto, o autor levanta a hipótese de que a melhor experiência em oferta de conteúdo contextual não seria resultado da utilização de muitos elementos na página, onde cada um deles priorize apenas um dos eixos de categorização, e sim uma quantidade menor de elementos que ofereçam conteúdo a partir de uma associação desses quatro eixos e da combinação de seus diferentes graus de relevância em relação ao conteúdo noticioso. 
Os dados apresentados ao longo deste artigo demostram que os sites de notícias ainda não apresentam mecanismos que automatizem a oferta de conteúdo de maneira satisfatória, no que diz respeito a disponibilizar uma landing page que substitua integralmente a experiência oferecida pelas homepages e conseguir efetivamente engajar o usuário que acessa diretamente a uma página de conteúdo. Nesse intuito, como futuros trabalhos, é possível atuar na pesquisa com usuários e na aplicação de testes de usabilidade para avaliar a importância que os usuários dão a cada um desses quatro eixos de categorização, de maneira a construir mecanismos para a oferta de conteúdo a partir de um mesmo elemento que leve em conta a relevância do ponto de vista do conteúdo, do corpo editorial, do usuário e da comunidade como um todo, otimizando ao máximo a experiência de consumo e navegação para o usuário que acessa o site a partir de uma origem externa.

\section{REFERÊNCIAS}

CSIKSZENTMIHALYI, M. Finding flow: The psychology of engagement with everyday life. Basic Books, 1998.

DELEUZE, G., GUATTARI, F. Mil Platôs: capitalismo e esquizofrenia. Vol. 1, 1997.

HAILE, Tony. What You Think You Know About the Web Is Wrong. Disponível na internet por http em: http://time.com/12933/what-you-think-you-know-about-theweb-is-wrong. Acesso em 10 mai. 2014

LEÃO, L. O Labirinto da Hipermídia: Arquitetura e navegação no ciberespaço. Editora Iluminuras. São Paulo, 1999.

LÉVY, P. Cibercultura. São Paulo: Ed. 34, 1999.

LOHMANN, A. Fluxos da navegação contextual na interação com o conteúdo noticioso. Anais do Interaction South America. 2013.

LONGHI, R. Metáforas e Labirintos: A Narrativa em Hipertexto na Internet. 1998. Dissertação (Mestrado). UFRGS/PPGCOM, Porto Alegre.

MITCHELL, Amy; PAGE, Dana. Social, search \& direct: pathways to digital news. Disponível na internet por http em: <http://www.journalism.org/files/2014/03/SocialSearchandDirect_PathwaystoDigitalN ews.pdf>. Acesso em 14 abr. 2014

MITCHELL, Amy; ROSENTIEL, Tom. What Facebook and Twitter Mean for News. Disponível na internet por http em: <http://stateofthemedia.org/2012/mobile-devicesand-news-consumption-some-good-signs-for-journalism/what-facebook-and-twittermean-for-news> Acesso em 10 abr. 2014

PARISER, Eli. Palestra "Tenha cuidado com os 'filtros-bolha' online", concedida pelo autor do livro "O Filtro Invisível: $O$ que a internet está escondendo de você". 